\title{
Addressing the ignored complication: chronic opioid use after surgery
}

\author{
Scott G Weiner
}

Department of Quality and Safety and Department of Emergency Medicine, Brigham and Women's Hospital, Boston, Massachusetts, USA

\section{Correspondence to} Dr Scott G Weiner, Brigham and Women's Hospital, Boston, MA 02115, USA;

sweiner@bwh.harvard.edu

Accepted 22 September 2020 Published Online First

28 September 2020

\section{Sinked}

- http://dx.doi.org/10.1136/ bmjqs-2020-011295

Check for updates

(c) Author(s) (or their employer(s)) 2021. No commercial re-use. See rights and permissions. Published by BMJ.

To cite: Weiner $S G$ BMJ Qual Saf

2021;30:180-182.
We are all familiar with the dictum 'primum non nocere'-first, do no harm. The Latin word 'nocere' is commonly interpreted as 'harm', but it shares a root with 'pain'-think 'nociceptor' as an example. But what happens when the treatment of pain becomes the source of the harm? Only recently, we have recognised that prescribing excess opioids to previously naïve patients who undergo surgery and subsequently become chronic users is a 'never event' that we must strive to avoid. ${ }^{1-3}$

I first learnt about this problem several years ago, not from a research report but rather from my son's soccer coach. He told me about his experience after a lumbar discectomy. After a straightforward outpatient procedure, he was sent home with a prescription for 30 tablets of oxycodone. For the first few days, he experienced expected discomfort and took oxycodone, ibuprofen and acetaminophen. After that, the pain improved, and he discontinued oxycodone after using about 10 tablets. That night, he experienced the worse sensation he ever had, including restlessness, chills and diffuse body aches. He took an oxycodone and nearly immediately felt better. The following morning, he was insightful enough to realise what was happening: he was experiencing opioid withdrawal.

In our discussion about this experience, we reflected on how rapidly the brain adapts to opioids and how quickly withdrawal can occur. We also considered what would happen to a patient who did not have this insight the following morning and who continued to take the prescribed opioids in order to avoid the symptoms of withdrawal. Some patients must think: 'The doctor gave me thirty tablets, so she probably expects me to need that many'. And with that, the simple, mundane act of writing a prescription, another case of iatrogenic opioid dependence occurs.

Prolonged opioid use after surgery is one of the most common surgical complications. ${ }^{4}$ A meta-analysis determined that, across 33 studies, $7 \%$ of patients continued to fill opioid prescriptions more than 3 months after surgery. ${ }^{5}$ However, it does not appear that this rate is the same for all opioid prescriptions, but rather is highly dependent on the quantity of opioids prescribed. In a large study evaluating opioid prescriptions to opioid-naïve patients for any indication, the likelihood of chronic opioid use increased with each additional day of medication supplied starting with the third day, reaching nearly $20 \%$ with a 10 days' supply. ${ }^{6}$ In my group's study of all opioid prescriptions in Ohio, we also discovered that about $8.6 \%$ of opioid-naïve patients who received an opioid prescription developed chronic use, and that the greater the opioid content of the prescription the more likely to lead to chronic use. ${ }^{7}$

The work in this issue by Brown and colleagues ${ }^{8}$ to reduce postoperative opioid prescriptions is therefore of utmost importance. A strength of this work is determining, in an evidence-based fashion, how many opioid tablets patients consumed after common procedures and then basing their recommendation on that actual experience. Not all surgical procedures incur the same amount of pain, so a one-size-fits-all approach would not make sense. By applying these guidelines across the state, they were able to change the standard of care and reduce opioid quantities by about $50 \%$.

But arbitrarily reducing quantities should not be the only goal. The authors therefore also evaluated patient-reported outcomes and discovered, paradoxically, that patient satisfaction with care 


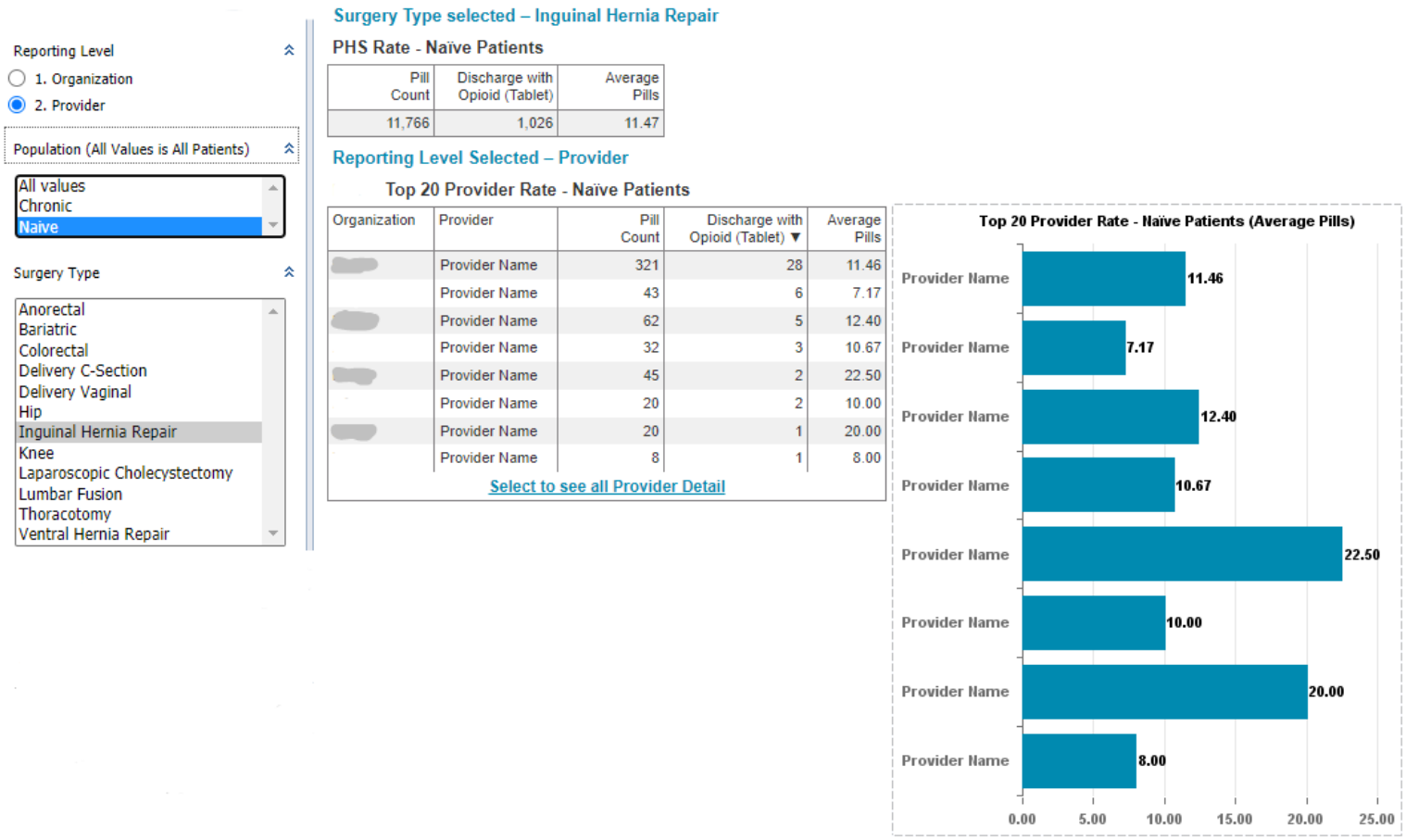

Figure 1 Sample dashboard evaluating opioid prescribing after common procedures. PHS, name of organisation.

increased as opioid quantities decreased, and postoperative pain scores were unchanged. This finding should put to rest, once and for all, the myth that decreasing opioid prescribing will lead to increased patient suffering and decreased patient satisfaction. Another study also found the same result, and the authors concluded that concern around satisfaction scores should not be a barrier to appropriately limiting opioid prescribing. ${ }^{9}$

Armed with the knowledge that postoperative prescribing can lead to long-term use, that opioid quantities can be safely reduced, and that patient suffering and satisfaction are not adversely affected, what are the next steps for a hospital willing to make this change? As a first intervention, knowing one's own data can be incredibly helpful. Our health system created a reporting tool to evaluate postoperative prescribing for 12 procedures (figure 1). We use this tool to evaluate guideline compliance and identify outlier prescribers. The prescription is attributed to the surgeon of record and we found significant variability even between surgeons in the group. Another key lesson we learnt is that, especially in the academic setting, it is infrequently the surgeon of record who is writing the discharge opioid prescription, but rather residents, nurse practitioners or physician assistants who have that responsibility. In some cases, our surgeons were surprised by the quantities of opioids being prescribed to their patients at discharge, and this knowledge became an impetus to implement prescribing guidelines for certain common procedures.

The next step is to choose a guideline to follow. The Michigan Opioid Prescribing Engagement Network (OPEN) programme, described in this issue's article, has been remarkably helpful by both sharing and regularly updating its guidelines. ${ }^{10}$ A multispecialty expert panel also created similar guidelines which are freely accessible. ${ }^{11}$ Once the guidelines are chosen, they should be shared with surgeons and other proceduralists, ideally at a faculty or educational meeting. Similar to the work described by Brown and colleagues, ${ }^{8}$ any intervention should be paired with patient education, including these six steps: set expectations, set norms, emphasise non-opioids first, discuss appropriate use, describe adverse effects of opioids and address safe disposal when opioids are no longer needed. ${ }^{12}$ Preprinted handouts given to patients can facilitate this discussion. This education should be part of the initial surgical consent process, in which potential complications of the surgery are explained to the patient. ${ }^{13}$

Additionally, prescribers should be instructed on performing a risk assessment prior to any opioid prescribing, such as accessing the patient's prescription drug monitoring programme data profile where available, and either using a standardised risk tool (eg, the Opioid Risk Tool ${ }^{14}$ ) or knowing patient-level factors that put one at risk for developing opioid use disorder, such as concurrent psychological disease and personal 
or family history of substance use disorders. Patients who have risk factors but still need surgery should not have adequate analgesia withheld, but the prescriber should exercise increased caution and closer follow-up when opioids are prescribed.

Finally, the effects of the intervention should be measured, including not just quantities of opioids prescribed but also patient satisfaction and incidence of other postoperative complications. Of note, some quality agencies have begun to take note of this issue. For example in the USA, for the Leapfrog Group's 2020 reporting, an optional field is to report on use of prescription drug monitoring programmes as well as whether or not surgeons are adherent to national evidence-based opioid prescribing guidelines. ${ }^{15}$ Their chosen tool is the Center for Opioid Research and Education (CORE) metrics, which are similar to Michigan OPEN's. For this year, the reporting is optional and not scored or publicly reported, but it is a first step towards keeping hospitals accountable and may become reported in future iterations.

In the work to reduce postoperative opioid prescriptions, a next step will be to evaluate the truly meaningful outcomes of interest: development of opioid use disorder and opioid-related overdose and death. It makes empiric sense that decreasing opioid prescriptions will decrease chronic opioid use and, in some cases, these complications. Furthermore, eliminating excess leftover tablets in the medicine cabinet can only be beneficial towards reducing diversion. It will take more time and research to evaluate these outcomes, but it should not stop implementation of programmes like these to reduce the harm associated with treating pain with opioids.

Funding SGW was supported by the National Institute on Aging (grant R56-AG059620) and the Agency for Healthcare Research and Quality (grant R01-HS026753).

Competing interests None declared.

Patient consent for publication Not required.

Provenance and peer review Commissioned; internally peer reviewed.

\section{REFERENCES}

1 Barth RJ, Waljee JF. Classification of Opioid Dependence, Abuse, or Overdose in Opioid-Naive Patients as a "Never Event". JAMA Surg 2020;155:543-4.
2 Hah JM, Bateman BT, Ratliff J, et al. Chronic opioid use after surgery: implications for perioperative management in the face of the opioid epidemic. Anesth Analg 2017;125:1733-40.

3 Neuman MD, Bateman BT, Wunsch H. Inappropriate opioid prescription after surgery. Lancet 2019;393:1547-57.

4 Brummett CM, Waljee JF, Goesling J, et al. New persistent opioid use after minor and major surgical procedures in US adults. JAMA Surg 2017;152:e170504.

5 Lawal OD, Gold J, Murthy A, et al. Rate and risk factors associated with prolonged opioid use after surgery: a systematic review and meta-analysis. JAMA Netw Open 2020;3:e207367.

6 Shah A, Hayes CJ, Martin BC. Characteristics of Initial Prescription Episodes and Likelihood of Long-Term Opioid Use - United States, 2006-2015. MMWR Morb Mortal Wkly Rep 2017;66:265-9.

7 Weiner SG, Chou SC, Chang CY, et al. Prescription and prescriber specialty characteristics of initial opioid prescriptions associated with chronic use. Pain Med.

8 Brown CS, Vu JV, Howard RA, et al. Assessment of a quality improvement intervention to decrease opioid prescribing in a regional health system. BMJ Qual Saf 2021;30:251-9.

9 Louie CE, Kelly JL, Barth RJ. Association of decreased postsurgical opioid prescribing with patients' satisfaction with surgeons. JAMA Surg 2019;154:1049-54.

10 Michigan Opioid Prescribing Engagement Network. Prescribing recommendations. Available: https://michiganopen.org/prescribing-recommendations [Accessed $18 \mathrm{Sep}$ 2020].

11 Overton HN, Hanna MN, Bruhn WE, et al. OpioidPrescribing guidelines for common surgical procedures: an expert panel consensus. J Am Coll Surg 2018;227:411-8.

12 Michigan Opioid Prescribing Engagement Network. Patient counseling. Available: https://michigan-open.org/prescribingrecommendations/patient-counseling [Accessed $18 \mathrm{Sep}$ 2020].

13 Scarlet S, McNicoll CG, Colosimo C, et al. Preoperative communication promotes opioid stewardship. Bulletin of the American College of surgeons, 2017. Available: https://bulletin. facs.org/2017/08/preoperative-communication-promotesopioid-stewardship [Accessed 18 Sep 2020].

14 Webster LR, Webster RM. Predicting aberrant behaviors in opioid-treated patients: preliminary validation of the opioid risk tool. Pain Med 2005;6:432-42.

15 Stewart KB. The Leapfrog group and updates to the 2020 Leapfrog surveys. Available: https://www.njhcqi.org/wpcontent/uploads/2020/02/2-6-Quality-Breakfast-LeapfrogSlides.pdf [Accessed 18 Sep 2020]. 